\title{
A BIOECONOMIA NO SÉCULO XXI: REFLEXÕES SOBRE BIOTECNOLOGIA E SUSTENTABILIDADE NO BRASIL
}

\author{
Romina Ysabel Bazán Barba* \\ Nivaldo dos Santos**
}

\section{Resumo}

Aborda-se, dentro do direito e sustentabilidade, pela vertente jurídico-sociológica, a problemática da Bioeconomia no Século XXI. Com base na dedução da pesquisa teórica, estuda-se como a biotecnologia vem assumindo a liderança entre os setores industriais e os novos desafios dessa economia que representa o futuro da humanidade. Objetiva-se analisar como a biotecnologia trará mais benefícios de ordem social, ambiental, econômico e cultural. Traçando-se um panorama das tendências atuais para os setores da saúde, energia (biocombustíveis), agricultura, alimentos e conservação dos recursos biológicos. Além disso, sua proteção, regulamentação e aplicação para o futuro no Brasil.

Palavras-chave: Bioeconomia; Biotecnologia; Biodiversidade; Direito; Sustentabilidade.

\section{BIOECONOMY IN THE 21st CENTURY: REFLECTIONS OF BIOTECHNOLOGY AND SUSTAINABILITY IN BRAZIL}

\begin{abstract}
Within the law and sustainability, the issue of Bioeconomy in the 21st Century is approached by the legal-sociological aspect. Based on the deduction of theoretical research, it is studied how biotechnology has been taking the lead among industrial sectors and the new challenges of this economy that represents the future of humanity. The objective is to analyze how biotechnology will bring more social, environmental, economic and cultural benefits. Tracing an overview of the current trends for the sectors of health, energy (biofuels), agriculture, food
\end{abstract}

\footnotetext{
*Advogada. Doutoranda em Biotecnologia e Biodiversidade pela UFG. Mestre em Direito pelo Programa de Pós-Graduação em Direito Agrário da UFG. Especialista em Direito Civil e Processo Civil pela ATAME/GO. Membro da Comissão de Direito Agrário da OAB/GO. Email: rominabazan92@gmail.com. <http://lattes.cnpq.br/3253119728025866>

${ }^{* *}$ Doutor em Direito pela PUC/SP. Possui financiamento pela FAPEG e IPOGDATA. Professor titular na UFG e PUC/GO. Secretário especial de Ciência e Tecnologia do Instituto Goiano de Direito Ambiental. E-mail: nivaldodossantos@ bol.com.br. <http://lattes.cnpq.br/3359203015249134>
} 
and conservation of biological resources. Also, its protection, regulation and application for the future in Brazil.

Keywords: Bioeconomy; Biotechnology; Biodiversity; Right; Sustainability.

\section{Introdução}

Em uma época de rápidas transformações, a preocupação global para com o desenvolvimento, os novos modelos tecnológicos e em contrapartida a fome, a injustiça social, as doenças, a violência contra os povos tradicionais, o processo acelerado de urbanização e a consequente destruição da diversidade biológica e o uso desenfreado de seus recursos, são algumas premissas que vêm avançando no decorrer da história.

A biodiversidade - todos os ecossistemas, biomas, recursos naturais e variedades de organismos, espécies, genes e seres vivos do planeta, bem como a sua conservação e os conhecimentos tradicionais associados - e a biotecnologia - meios tecnológicos de transformação e manipulação de microrganismos, plantas, animas e outras formas de vida e os conhecimentos científicos empregados - possuem uma íntima relação inserida em suas próprias definições teóricas e aplicações práticas.

A biotecnologia extrai da diversidade biológica todos os materiais necessários para criar, transformar e modificar através de processos tecnológicos o meio em que se vive, seja para fins agrícolas, fármacos, medicamentos, alimentos ou até cosméticos. Logo, a biotecnologia depende da biodiversidade para existir.

Por sua vez, a biotecnologia cria valores de mercado para a biodiversidade. A biodiversidade é a fonte de matéria prima (informações genéticas) e conhecimento tradicional associado para a biotecnologia criar, por meio de diversos estudos tecnológicos, algum determinado produto para venda, consumo ou ainda desenvolver algum processo específico que fará parte de outro fim. Recordando a clássica obra de Karl Polanyi da transformação da terra e natureza, em mercadorias.

O Brasil, detentor de um dos maiores acervos biogenéticos do mundo, precisa assegurar a conservação de seus recursos por meio de um modelo econômico de desenvolvimento que seja sustentável. Nesse sentido, o Brasil possui uma regulamentação interna pela própria Constituição Federal de 1988, bem como tratados internacionais 
ratificados, como a Convenção de Diversidade Biológica de 1992 e internamente a Lei da Biodiversidade ( ${ }^{\circ}$ 13.123/2015) que representa o novo marco regulatório do tema.

O maior bem econômico da atualidade, século XXI, é o conhecimento. A biodiversidade possui um papel importantíssimo nesse cenário, pois a ela está intrínseco uma série de conhecimentos riquíssimos que ainda sequer foram todos descobertos e estudados. Assim, um modelo de economia que tenha a biodiversidade como foco de estudo, análise e desenvolvimento, possui um enorme potencial econômico para o futuro.

Nesse sentido, surge a ideia da bioeconomia que, por meio de pesquisas e inovações tecnológicas dentro das ciências biológicas (biodiversidade) incentiva uma atividade econômica que possa beneficiar a todos. É através da bioeconomia que se desenvolvem medicamentos novos, tratamentos para doenças antes intratáveis, biocombustíveis e alimentos seguros e com maior rendimento na produção agrícola.

Ideias e práticas inovadoras com conhecimento científico e tecnológico aplicados usando a biodiversidade para alcançar saúde, segurança alimentar e fontes renováveis de energia é o que mais se deseja por meio da bioeconomia. Isto posto, o binômio que se pretende obter é o progresso econômico pelo uso sustentável dos recursos por meio das biotecnologias.

Tendo em vista as peculiaridades do tema proposto, a presente pesquisa pode ser tratada perante diversos enfoques - científico, jurídico, tecnológico, social, ambiental etc. inserindo-se dessa forma, como uma investigação sob a perspectiva interdisciplinar.

Sendo o sistema normativo uma variável que dependente do meio social e que se preocupa com a relação entre legislação e sociedade. Analisa-se assim, a problemática envolvendo as biotecnologias e atual tendência da bioeconomia frente ao desenvolvimento sustentável.

Quanto aos processos mentais que propiciam o estudo desta pesquisa, utiliza-se o raciocínio dedutivo, por meio do qual, faz-se uma pesquisa teórica junto à doutrina, estudos científicos e legislação, buscando-se compreender as questões sociais e ambientais relacionadas a bioeconomia e biotecnologia. Desta forma, a dedução será utilizada para se concluir algo que não ultrapasse as premissas abordadas no material coletado, de forma que a conclusão é uma decorrência lógica das premissas. Finalmente, se utiliza o raciocínio dialético no estudo crítico da realidade prática, através de uma síntese crie-se uma tese (os aspectos positivos da atual tendência mundial pela bioeconomia) e uma antítese (os aspectos negativos do uso 
indiscriminado das biotecnologias e seus possíveis malefícios para a biodiversidade, comunidades locais e saúde humana).

\section{Bioeconomia para o Século XXI}

A natureza é espontaneamente uma economia circular, nela nada se perde, tudo se transforma, se recicla, se renova e assim sucessivamente. Esse modelo ideal de um sistema econômico circular é o que se pretende atingir através da bioeconomia.

Setores antes nocivos pelo fluxo naturalmente degradante do uso de recursos biológicos escassos, hoje, por meio de biotecnologias há uma melhora na produção primária industrial e um resultado de resíduos menos prejudiciais para o meio ambiente e para a saúde humana, por exemplo, o uso das biomassas e os biocombustíveis.

Bill Devall (2006, p. 61) afirma: "Biodiversity is not only defined by scientists, it is also defined in various social contexts, including legal, social, political, and cultural contexts." Isto é, a biodiversidade não se limita ao campo científico, mas permeia diversas áreas do conhecimento. A biodiversidade está inserida em um contexto social amplo, em que a humanidade é totalmente dependente.

Os conhecimentos tradicionais associados de comunidades locais, como tribos indígenas e camponeses por exemplo, fazem parte, compõem a biodiversidade de uma determinada região ou localidade e muitas vezes são subtraídos por cientistas a fim de produzirem conhecimentos científicos sobre determinado assunto. A atual proteção destes conhecimentos por meio da justa e equitativa repartição dos benefícios também é um avanço dos últimos tempos e que, deve estar presente no contexto da bioeconomia.

A biotecnologia representa uma resposta da comunidade científica em tentar desvendar, analisar e decodificar os conhecimentos contidos na própria diversidade biológica. Socialmente, os avanços da biotecnologia trouxeram inúmeros benefícios para a humanidade, como descobertas vacinas, cura para doenças, diversos tratamentos, melhorias para a agricultura, para os alimentos etc. Sendo que todos esses avanços produzem também uma grande riqueza econômica para os países que a desenvolvem.

Assim, os avanços da bioeconomia juntamente com a biotecnologia serão fundamentais para a conservação e manutenção da diversidade biológica e da economia para as próximas décadas. 
A Convenção sobre Diversidade Biológica (CDB), importante instrumento internacional sobre o tema visa primordialmente à conservação de toda a biodiversidade existente, através do uso sustentável dos recursos naturais e pela justa e equitativa distribuição dos benefícios desse uso. Mesmo com o advento da Lei de Biodiversidade ( ${ }^{\circ} 13.123 / 2015$ ) o quadro legislativo brasileiro de acesso ao patrimônio genético tem-se mostrado insuficiente para evitar práticas de exploração predatória e o contrabando de espécies naturais, como também a apropriação e monopolização da natureza e de seus conhecimentos tradicionais como uma forma de mercadoria. Nesse sentido, a criação de um plano nacional brasileiro sobre bioeconomia e biotecnologia seria ideal para resguardar e regulamentar mais esses temas.

A situação conflitante, mas necessária de ser enfrentada entre progresso (desenvolvimento) e conservação (sustentabilidade) é um dos temas mais discutidos na atualidade. Sob a perspectiva da diversidade biológica, seu uso e manutenção, nota-se o crescente interesse mundial na bioeconomia como solução para essa questão.

Os países desenvolvidos têm voltado seus olhos cada dia mais para a aplicação da bioeconomia. Os Estados Unidos por exemplo, possui um Plano Nacional de Bioeconomia incrível, desde 2012 criado pela administração do então presidente Obama, para fomento e implementação da bioeconomia no país, regulamentação esta que não se possui ainda no Brasil, todavia serve como inspiração para que possa ser futuramente desenvolvida e implementada.

Desse National Bioeconomy (THE OBAMA ADMINISTRATION, 2012) destacamse alguns pontos relevantes, como por exemplo, o incentivo aos biocombustíveis, plásticos biodegradáveis, biomassas renováveis, biotecnologia industrial, bioinformática, bioinvenções, engenharia biomolecular, bioquímica, biomedicina e outros diversos termos que acompanham o prefixo "bio" que significa vida e tudo que esteja relacionado a seres vivos. Nesse sentido, observa-se que o futuro da humanidade caminha em aproximar, em unir todos os processos de conhecimentos e inovação aos processos biológicos.

Haja vista que é da própria diversidade biológica que a maioria, senão todos, os conhecimentos são extraídos, para posteriormente serem modificados e melhorados para determinados fins.

Aprecia-se também o grande investimento financeiro feito por parte do governo americano nesse plano (THE OBAMA ADMINISTRATION, 2012), seja com benefícios fiscais à empreendedores e empresas, concessão de bolsas universitárias, parcerias entre indústrias e pesquisadores universitários, transferência de tecnologias, desburocratização do 
sistema, redução de barreiras e rapidez nos processos, para que nenhuma ideia ou empreendimento inovador no campo da bioeconomia ficasse de lado.

O progresso com incentivo a descobertas com potencial científico transformador e de altos rendimentos econômicos para o país é o que a potência americana almeja alcançar por meio desse plano nacional. Para tanto, o documento elenca algumas tendências da bioeconomia por setores, como saúde, energia, meio ambiente etc., os quais, serão brevemente abordados trazendo-se possibilidades e aplicações para o Brasil neste século XXI.

\subsection{Tendências da bioeconomia e biotecnologia na Saúde}

No campo da saúde vale ressaltar que todos os avanços e processos de urbanização advindos desde a Revolução Industrial, trouxeram consigo além de perdas da biodiversidade, o surgimento de várias doenças globais como destaca Pongsiri et al. (2009, p. 952)

\footnotetext{
Along with increasing mobility, demographic change, and anthropogenic disturbance, we appear to be undergoing a distinct change in global disease ecology [...] Clearly, there is a need for improved healthmonitoring of human populations in at-risk areas where population growth is high, ecologically disruptive development is under way, and human and wildlife overlap considerably.
}

Nesse sentido, a biotecnologia juntamente com outros setores da ciência e saúde vem avançando no descobrimento de medicamentos, tratamentos e vacinas específicas para cada tipo de doenças. A produção de fármacos e biofármacos movimenta uma expressiva parcela da economia mundial, com altos rendimentos para as empresas desse setor.

Uma abordagem promissora na bioeconomia para a saúde destacada no plano americano é o avanço desde o The Human Genome Project da criação de uma medicina personalizada, na qual, o genoma do paciente seria analisado para que os tratamentos fossem cada vez mais específicos para cada indivíduo. Como também, aponta o fomento para parcerias público-privadas na criação de novos medicamentos (mais inteligentes) e o combate específico da doença de Alzheimer. (THE OBAMA ADMINISTRATION, 2012, p. 9 e 44)

A aplicação da biologia sintética para a produção de medicamentos também é um ponto de destaque. Por meio da criação artificial de organismos antes extraídos apenas da natureza, sem a necessidade de derrubada de árvores e desmatamento de plantas, contribuindo assim para a manutenção da diversidade biológica. 
No Brasil, os avanços da biotecnologia para o setor da saúde estão presentes nas "vacinas preventivas e terapêuticas; substâncias terapêuticas de base biotecnológica, como proteínas recombinantes, anticorpos monoclonais e hemoderivados recombinantes; e reagentes e kits de diagnóstico." (DIAS e CARVALHO FILHO, 2017, p. 422).

Nesse sentido, nota-se a importância do uso da biotecnologia no campo da medicina, seja para o diagnóstico precoce de doenças, uso de células tronco, supressão de células cancerígenas, vacinas, biofármacos, geneterapia, dentre outros. Sendo este setor uma forte tendência para a bioeconomia, incentivando-se novos projetos e descobertas para a promoção não só da saúde humana e ambiental, mas também do desenvolvimento econômico e criação de mais empregos.

\subsection{Tendências da bioeconomia e biotecnologia na Energia}

A produção de energias renováveis, limpas e biocombustíveis nunca estiveram tão em alta como atualmente. A capacidade por meio da biotecnologia de descobrir novas fontes de energia e controlá-las é o que mais se pretende neste ponto.

Historicamente, desde 1970 foram adotadas, no Brasil, medidas para a produção dessas fontes opcionais de energia limpa, como a criação do Programa Nacional de Álcool (Proálcool). Em 2005 também houve o lançamento do Plano Nacional de Energia visando a ampliação da produção de biocombustíveis. Todavia, até hoje as crises do petróleo perduram. As oscilações nos preços do petróleo permitiram que o Brasil investisse mais na produção de etanol, visando seu autoabastecimento e tornando-se menos dependente de uma fonte de energia limitada. Os avanços tecnológicos também contribuíram para essa independência, como a chegada dos carros do tipo "flex" no Brasil.

Assim, a bioeconomia pretende diminuir ainda mais a dependência em combustíveis a base de carbono como se produzem nas refinarias tradicionais. A tendência atual são as biorrefinarias, os biocombustíveis de segunda geração, que não dependem mais dos alimentos puros (primeira geração), mas que fazem a conversão de biomassas em combustíveis. Sendo que, as biomassas são obtidas de vários tipos de resíduos agrícolas (vegetais, plantas, sementes, frutos etc.) que seriam inicialmente descartados, utilizando-se enzimas sintéticas para transformá-las em energias limpas. O Brasil, sendo um dos maiores produtores de etanol do 
mundo precisa assegurar ainda mais sua participação na bioeconomia neste setor, importando menos e produzindo mais.

Nesse ponto, o Brasil se destaca pela produção de cana de açúcar, milho, soja que produzem a maior parte dessas biomassas, como também, as indústrias de papel e celulose que geram vários resíduos durante o processo produtivo. Dentre diversas plantas como o pinhão, araucaria que servem também para lenha e produção de biocombustíveis. À vista disso, a biodiversidade presente no Brasil também o coloca à frente, por exemplo, uma enzima recentemente descoberta na Amazônia (Beta Glicosidase) quando usada na produção de etanol da cana de açúcar apresentou uma maior produtividade de até cinquenta por cento. (NOBRE e NOBRE, 2019, p.13)

Assim, a biotecnologia busca a cada dia a geração de energias limpas por meio de fontes renováveis já presentes na natureza. Como bem aponta o plano nacional americano "even solar energy conversion has the potential to be transformed through increased understanding of biological approaches to solar-energy capture.” (THE OBAMA ADMINISTRATION, 2012, p. 10) Ou seja, mesmo as formas de energia renováveis que já se conhecem na atualidade, podem se beneficiar com os avanços e estudos biotecnológicos, promovendo a manutenção da biodiversidade e trazer maiores rendimentos econômicos.

\subsection{Tendências da bioeconomia e biotecnologia no setor Agrícola e Alimentar}

Os setores da agricultura e da produção de alimentos são diretamente beneficiados pelas novas biotecnologias e representam um campo extremamente promissor para a bioeconomia.

No campo, pragas antes incontroláveis que dizimavam plantios inteiros passam a ser combatidas de diversas formas, seja por meio de pesticidas ou ainda organismos geneticamente modificados (transgênicos) multirresistentes. Os biofertilizantes, a clonagem, plantas resistentes a diversos tipos de climas e os alimentos melhorados com suplementos vitamínicos.

Industrial uses for biotechnology extend well beyond health and agriculture. The industrial biotechnology sector uses genetically modified microbes as "cell factories" to produce a diversity of commercial products including vitamins, natural preservatives, biobased polymers, and enzymes for cleaning and textile industries, among many others.Given the vast array of different products, accurate economic numbers that represent industrial biotechnology's impact on these products are difficult to ascertain. (THE OBAMA ADMINISTRATION, 2012, p. 14) 
O uso excessivo de agrotóxicos, também relacionado a estes problemas, visto que, geram malefícios tanto para saúde humana como para ao meio ambiente, poluindo o solo e atingindo os recursos hídricos pelos rejeitos da agricultura e pelas chuvas. As pragas que muitas vezes fazem parte de toda uma cadeia da diversidade biológica são atingidas diretamente, como também, outros organismos vivos que não necessariamente estariam ameaçando aquele determinado plantio sofrem dos malefícios dos pesticidas.

Tendo em vista essas questões, sabendo-se que com o incremento populacional a demanda por mais alimentos dentro dos próximos anos pode aumentar significativamente, possuindo-se a mesma área cultivável, a biotecnologia dentro dos padrões de preservação ambiental, produtividade, menos perdas e alimentos nutricionalmente beneficiados é a tendência para a atual bioeconomia.

A bioeconomia no setor agrícola e alimentar visa também combater a pobreza, fome e desnutrição. Para tanto, a biotecnologia é implementada nos plantios e alimentos, respeitando as normas e padrões da segurança alimentar para obter avanço social e econômico. A segurança é o ingrediente mais importante nos alimentos. Portanto, deve haver transparência nas discussões sobre os riscos e benefícios de cada incremento tecnológico na produção de determinado alimento.

Nesse sentido, tratando de transparência, quanto aos transgênicos e toda a polêmica que os envolvia nos últimos anos sobre se eram ou não maléficos para os seres humanos, em 2016 repercutiu na mídia um estudo de mais de novecentos casos durante vinte anos feito por diversos cientistas renomados da área no Comitê de Culturas Geneticamente Modificas nos EUA comprovando que os mesmos não causam dados à saúde humana. (NATIONAL ACADEMIES OF SCIENCES, ENGINEERING, AND MEDICINE).

Além do que, os benefícios biotecnológicos de melhorias para os plantios e alimentos aceleram processos que demorariam anos se feitos da maneira tradicional, todavia, a transgenia não exclui o tradicional método de melhoramento das plantas, ambas coexistem e caminham juntas para proporcionar benefícios tanto de ordens sociais como econômicas.

1.4 Tendências da bioeconomia e biotecnologia para o Meio Ambiente 
A preservação da biodiversidade - presente na biotecnologia por meio de métodos de identificação, codificação e clonagem - e eliminação dos agentes poluidores do meio ambiente - através das chamadas biorremediação e biodegradabilidade, visando a recuperação de áreas degradadas. É fundamental para os avanços tecnológicos e da bioeconomia do século XXI que o meio ambiente (ar, água, alimentos, animais, plantas, solo, matérias-primas etc.) esteja conservado e equilibrado.

Desde o advento do conceito de "desenvolvimento sustentável", todos os avanços tecnológicos devem compreender a visão de que os recursos biológicos precisam ser preservados para esta e para as futuras gerações.

Cumpre salientar que a aplicação da biotecnologia em todos os setores supramencionados visa atender a demanda mundial por saúde, alimentos, empregos etc., mas que em todos estes deve-se reduzir os impactos ambientais. O bem estar da humanidade depende diretamente de um ambiente saudável.

Nesse sentido, tecnologias de monitoramento dos impactos são criadas (biossensores), como também técnicas menos agressivas para a agricultura, manejo e extração dos recursos biológicos. O descarte e reaproveitamento dos resíduos também representam um desafio nesse setor.

The well-being of the living world and its ability to provide sustainable resources depend on responsible human stewardship, which in turn requires fundamental knowledge. Basic and applied biological research has the potential to produce a whole generation of the new knowledge and technologies needed to understand how the living world functions, to monitor and mitigate human impact, and to develop informed approaches to use and restore environments. (THE OBAMA ADMINISTRATION., 2012, p. 11)

A biotecnologia também possui como fundamentos a gestão e restauração ambiental dos males já causados. Microrganismos e enzimas são formulados em laboratórios para desintoxicar resíduos e despoluir ecossistemas. O setor de restauração ambiental e uso sustentável dos recursos são a chave para o avanço da bioeconomia no campo ambiental.

A nanotecnologia vem gerando alguns problemas de ordem ambiental, a exemplo, os anticoncepcionais amplamente utilizados pelas mulheres no mundo todo, sendo que sua eliminação pelo corpo contamina as águas e o meio ambiente. Nesse sentido, os estudos biotecnológicos precisam avançar para minimizar os impactos causados por esses tipos de medicamentos relativamente novos, mas que vem gerando danos. 
O Brasil, no setor ambiental também é destaque, por ser a última fronteira agrícola do mundo, haja vista sua vasta área cultivável e em parte preservada. Embora a agropecuária tenha causado danos ambientais em boa parte do país, ainda existem boas áreas cultiváveis, diferentemente que no restante do mundo, onde já foram muitas vezes esgotadas e dizimadas.

Embora o agronegócio brasileiro promova uma expressiva parcela da economia do país, seu avanço para as florestas (antes repletas de diversidade biológica) transformando-as em pastos para simples criação e abatimento de gado, como vem acontecendo inclusive na Amazônia, representam um grande risco ambiental para a biodiversidade. Podendo gerar riscos de extinção de espécies, como também afeta a fauna e flora, produzindo erosão e perda da fertilidade dos solos. Nesse ponto, o que se deve aprimorar através dos estudos biotecnológicos são medidas que visem a redução desses riscos, novas formas de reaproveitamento do solo e investimentos em produtividade, visando a utilização de menos áreas para produzir mais.

Biomas brasileiros como o cerrado e o pantanal riquíssimos em biodiversidade, sequer conhecida completamente, está virando cinzas nos últimos tempos devido as queimadas. Nesse sentido, os avanços tecnológicos podem e muito contribuir no monitoramento e combate das queimadas e poluições através dos biossensores.

Outro ponto de destaque são os investimentos em biotecnologias para o reaproveitamento das mencionadas biomassas de diversos resíduos agrícolas produzidos pelas atividades humanas. Em última análise, a recuperação dos ecossistemas por meio da biotecnologia poderá minimizar os impactos ambientais como as mudanças climáticas, extinção de espécies e plantas, reduzir e controlar as mencionadas doenças globais.

\section{Reflexões sobre biotecnologia e sustentabilidade}

Por trás de todos esses avanços biotecnológicos existem vários discursos muitas vezes de índole ideológica e sociológica que, impendem um maior avanço nesse ponto, para tanto apresentam-se aqui como uma breve reflexão.

O chamado "antidesenvolvimento" que tem por base a ideologia descrita pela autora indiana Vandana Shiva (2003, p. 10) em sua obra "Monoculturas da mente", tem a capacidade de gerar convicção na sociedade de que este modelo atual é o único que pode solucionar os problemas em todos os locais de igual maneira.

Essa ideologia traz consigo valores com técnicas, políticas, programas e estratégias para que nos países do hemisfério Sul - em particular os países pobres, tenham instaurado um 
"antidesenvolvimento" agrícola e florestal, para que se tornem dependentes economicamente e tecnologicamente, de forma forçada.

Além do mais, a chamada "monocultura mental” gera uma ruína dos conhecimentos milenares da humanidade, dando ao saber científicos uma exclusividade e domínio sobre os novos modelos de produção. As multinacionais geram um controle ideológico, econômico e sociocultural para

[...] convencer as pessoas e as instituições que os sistemas tradicionais de produção são ineficazes para a abundância e ineficientes para o mercado, que não há outro sistema melhor que o da biotecnologia e da monocultura intensiva e que é inútil querer opor-se a elas ou procurar outra solução. [...] Por meio das monoculturas da mente, a exploração dos mais fracos é assegurada e o modelo hegemônico do antidesenvolvimento é confirmado (SHIVA, 2003, p. 11).

Em contrapartida, o desenvolvimento verdadeiro é aquele que respeita a diversidade biológica, os conhecimentos tradicionais e é socialmente sustentável. O problema situa-se no campo da vontade e do poder político e econômico para que os moldes do desenvolvimento sustentável sejam realmente efetivados.

A uniformização de espécies, por meio da monocultura, na qual, grandes conglomerados industriais investem em plantios de monoculturas geneticamente modificadas. As vantagens compreendem o progresso econômico, o aumento na produção agrícola, diminuição do desabastecimento e de perdas devido as sementes transgênicas resistentes.

Contudo, esse sistema representa para muitos o extermínio da diversidade biológica na localidade em que é implementado. Além disso, em razão da padronização genética se alguma doença atingir tal plantio haveria uma perda da totalidade daquela safra.

Sobre esse risco, Shiva aduz $(2003$, p. 17) que a uniformidade frente à diversidade biológica não é apenas um modo de produção, mas também uma forma de pensar e de se viver. Para Shiva, a monocultura não combate os problemas envolvendo alimentos, mas produz ainda mais escassez e pobreza, pela destruição da diversidade e das alternativas, havendo um monopólio de poder por parte dos conglomerados econômicos.

Modernamente a biodiversidade, se tornou passível de ser reproduzida biotecnologicamente. Nesse sentido, as questões envolvendo direitos de propriedade intelectual são levantadas, haja vista, que esses novos modelos tecnológicos que "criam vida" (Organismos Geneticamente Modificados) podem ser patenteados por seus criadores. 
Os direitos de propriedade intelectual protegem conhecimento técnico-científico, porque este significa riqueza; mas é interessante salientar que tais direitos só podem reconhecer valor no conhecimento técnico-científico moderno, uma vez que a própria ciência desqualifica e, literalmente, desvaloriza todos os outros saberes e práticas, tomando-os como simples matéria-prima, ou meros dados para a sua operação de valorização. Nesse ponto, cabe a pergunta: Por que só o conhecimento e a inovação moderna merecem proteção? Por que não conferir direitos sobre todo e qualquer tipo de conhecimento e inovação? (SANTOS, 1996, p.2)

Os direitos antes coletivos foram privatizando-se, as mentes criativas se tornaram fantoches do mercado, dando monopólios às criações lucrativas em detrimento do bem comum. É um falso argumento dizer que sem os Direitos de Propriedade Intelectual não há criatividade, pois não há incentivo - lucro. Em verdade, todas as culturas tradicionais e seus mais arraigados conhecimentos não visam ao lucro, mas sim um "bom viver" em comunidade, com compartilhamento e preservação, sem sigilos, sem exclusividades, tudo é comum a todos.

Com relação a este "bom viver", "direito ao bem viver" ou ainda "buen vivir" merece destaque, pois, representa um dos grandes pilares das constituições latino-americano, um ideal percebido "nos saberes, na tradição, na cultura indígena, sob diferentes aspectos" (CANOTILHO e LEITE, 2015, p. 484).

“A concepção do bem viver é parte essencial da cultura milenar dos povos originários da América Latina, integrando sua visão de mundo e se mantendo vigente em muitas comunidades indígenas até a atualidade" (CANOTILHO e LEITE, 2015, p. 484). Este ideal remete a uma convivência harmônica, que dirige a vida em plenitude e de equilíbrio com a natureza, defende o direito a uma existência digna a todos e proclama o dever de manutenção da vida.

É possível notar, então, que, no plano constitucional, Equador e Bolívia tiveram um importante avanço tanto na proteção constitucional do meio ambiente quanto no reconhecimento e valorização dos povos que compõem esses Estados (plurinacionais). A afirmação de um direito ao bem viver contribui para a integração desses pilares (direito da natureza e plurinacionalidade) e aproxima o Estado de seu dever de manutenção das condições essenciais para o desenvolvimento da vida, em todas as suas manifestações (CANOTILHO e LEITE, 2015, p. 488).

\section{Conclusão}

A bioeconomia é fundamentalmente o uso de pesquisas e inovações biotecnológicas, gerando atividades econômicas com benefícios públicos. Seus benefícios são inúmeros como os já mencionados do decorrer do trabalho, para o campo da saúde pela criação de novos 
medicamentos, diagnósticos e tratamentos de doenças; para a agricultura e produção de alimentos com maior rendimentos e alimentos mais nutritivos; no campo energético os biocombustíveis e energias limpas; para o meio ambiente usando-se biologia sintética e biossensores de monitoramento.

Um dos desafios da bioeconomia é fazer com que os produtos advindos da biotecnologia e conhecimentos científicos provenientes da diversidade biológica sejam valorizados, mais bem compreendidos e utilizados em todo o mundo, não apenas na economia global como também, para melhorar a vida humana e a economia local.

As bioindústrias, que utilizam da tecnologia para a produção de bens e serviços a partir da biodiversidade devem ter em mente a tendência atual da bioeconomia no compartilhamento de pesquisas e tecnologias, parcerias público-privadas e até colaborações entre empresas que são "concorrentes", afim de reunir recursos para alcançar inovações, na qual ambas se beneficiariam. Notoriamente, no decorrer do século XXI essas parcerias vêm aumentando em resposta a todas essas mudanças no campo da ciência, economia e tecnologia.

Outro ponto em que o Brasil necessita investir mais são nas parcerias entre universidades e empresas, ou seja, que os universitários possam ter um apoio de uma empresa privada nas suas pesquisas e inovações, esses apoios são bastante comuns na Europa e nos Estados Unidos, inclusive faz parte do plano nacional para a bioeconomia interna americana.

O Brasil, possuidor de um dos maiores acervos biogenéticos do mundo, precisa não apenas assegurar a proteção ao uso e compartilhamento de seus recursos, como também, investir no setor da bioeconomia, regulamentando a questão internamente, fortalecendo as pesquisas e inovações biotecnológicas. Buscando-se uma redução de atividades poluidoras e colaborando para a sustentabilidade.

Inspirando-se no modelo do plano nacional de bioeconomia americano, com incentivos ao empreendedorismo desde as faculdades, formar e capacitar mais seus técnicos de laboratórios, dar maiores incentivos aos estudos e pesquisas, por meio de bolsas e treinamentos qualificando a força de trabalho para a bioeconomia. Contribuindo para a bioinovação, propiciando uma aceleração na criação e desenvolvimento de produtos e inovações do laboratório para o mercado.

Propõe-se que os conhecimentos dotados de criatividade devem estar inseridos em três níveis de ciências da vida, primeiramente a criatividade própria dos seres vivos, seja de evoluir ou procriar; posteriormente a criatividade das comunidades tradicionais, de conservação e 
diferentes meios de utilização dos recursos naturais; e, por fim a criatividades dos cientistas modernos, que desenvolvem tecnologias destes dois níveis de ciência anteriores, que são capazes de beneficiar a vida humana, a natureza e a economia.

A ciência em si é a expressão de criatividade humana, seja ela individual ou coletiva, pois engloba diversas maneiras de conhecer o mundo. Todavia, as ciências autóctones nãoocidentais são ofuscadas pela hegemonia cultural e econômica da ciência ocidental moderna. Por esta razão, deve-se no contexto da bioeconomia dar maior importância e reconhecimento à pluralidade de saberes e tradições que são essenciais para a manutenção das diversas formas de vida num período de intensa destruição ecológica.

Haja vista as reflexões trazidas neste artigo, demostra-se que a proteção das biotecnologias não necessita ser restrita e há como se ter o compartilhamento desses novos conhecimentos em benefício da humanidade. Pois, os direitos de propriedade intelectual são eficientes em colher os produtos da criatividade social, mas ineficientes em criar e alimentar esses conhecimentos. Busca-se então, a não violência e a não usurpação dos conhecimentos, e sim o verdadeiro cultivo e uma real preservação da biodiversidade.

Incentivando-se assim, as transferências de conhecimento e tecnologias, valorizandose os conhecimentos tradicionais, visto que por meio deles muitos conhecimentos e inovações tecnológicas ainda decorrerão. Quanto ao sistema brasileiro em relação as implementações biotecnológicas para a bioeconomia do futuro, deve-se buscar uma diminuição das barreiras burocráticas do sistema, facilitando a pesquisa no campo de inovações sustentáveis (biológica, social, econômica e ambiental). Sendo assim, a proteção da biodiversidade é tão importante quanto o progresso, haja vista todos os pontos levantados para a manutenção da vida na terra e da saúde humana.

Em resposta às problemáticas levantadas na pesquisa, deduz-se que os impactos da biotecnologia nos recursos biológicos trarão mais benefícios em relação aos malefícios já ocasionados no passado. Tem-se que no passado pouco se preocupavam sobre as consequências da intervenção humana na diversidade biologia, todavia, atualmente observa-se que a conscientização e a informatização se tornam cada vez mais globalizadas. Mesmo que para alguns o lucro seja mais relevante que a preservação da biodiversidade, o atual sistema normativo, o poder de fiscalização do Estado e também da própria sociedade, poderão exigir desses indivíduos o comportamento desejado. 
Conclui-se, que através da bioeconomia a humanidade alcançará a cada dia mais conhecimentos suficientes para a criação de novas tecnologias devidamente sustentáveis, necessárias para satisfazer e abastecer a todos sem provocar impactos significativos no meio ambiente e sem passar pelo direito das minorias.

\section{Referências Bibliográficas}

\section{BRASIL. Constituição Federal de 1988.}

BRASIL. Lei $\mathbf{n}^{0}$ 13.123, de 20 de maio de 2015 (Lei da Biodiversidade). Disponível em: <http://www.planalto.gov.br/ccivil_03/_Ato2015-2018/2015/Lei/L13123.htm>. Acesso em: 20/09/2020.

BRASIL. MINISTÉRIO DO MEIO AMBIENTE - MMA. A Convenção sobre diversidade biológica - CDB. Cópia do Decreto Legislativo no. 2, de 5 de junho de 1992. Brasília - DF, 2000. Disponível em: 〈http://www.mma.gov.br/estruturas/sbf_dpg/_arquivos/cdbport.pdf> Acesso em: 23/09/2020.

CANOTILHO, José Joaquim Gomes e LEITE, José Rubens Morato (Orgs.). Direito Constitucional Ambiental Brasileiro. 6 Ed. Ver. São Paulo: Saraiva, 2015.

DEVALL, Bill. Conservation of Biodiversity: Opportunities and Challenges. Society for Human Ecology, Human Ecology Review, Vol. 13, No. 1, Arcata: CA, 2006.

DIAS, Rodnei Fagundes e CARVALHO FILHO, Carlos Alberto Aragão de. Bioeconomia no Brasil e no Mundo: Panorama Atual e Perspectivas. Revista Virtual de Química. Volume 9. Número $1.2017 . \quad$ p. 410-430. Disponível em: $<$ https://www.researchgate.net/profile/Rodnei_Dias/publication/313812849_Bioeconomy_in_ Brazil_and_in_the_World_Current_Situation_and_Prospects/links/58aad6fb92851cf0e3c71cd $\mathrm{d}$ /Bioeconomy-in-Brazil-and-in-the-World-Current-Situation-and-Prospects.pdf $>$. Acessado em: 25/09/2020.

GARI, Josep-Antoni. Biodiversity conservation and use: Local and global considerations. School of Geography, University of Oxford, Oxford, OX1 3TB, UK, 2000. Disponível em: <https://www.researchgate.net/publication/237543585_Biodiversity_conservation_and_use_L ocal_and_global_considerations> Acessado em: 22/09/2020.

GUSTIN, Miracy Barbosa de Sousa; DIAS, Maria Tereza da Fonseca. (Re)pensando a pesquisa jurídica: teoria e prática. Belo Horizonte: Del Rey, 2010.

NOBRE, Ismael e NOBRE, Carlos. Projeto "Amazônia 4.0": Definindo uma terceira via para a Amazônia. In: Futuribles em português. Número 2 - São Paulo - Plataforma Democrática - Fundação Fernando Henrique Cardoso, 2019. Disponível em: <http://www.plataformademocratica.org/Arquivos/Futuribles2/Futuribles2_ProjetoAmaz\%C3 \%B4nia4.0.pdf>. Baixado em: 23/09/2020. 
POLANYI, Karl. A Grande transformação: as origens de nossa época. $12^{\circ}$ ed. Rio de Janeiro: Elsevier, 2000.

PONGSIRI, Montira J. et al. Biodiversity Loss Affects Global Disease Ecology. University of California. BioScience. Vol. 59 No. 11. 2009.

SANTOS, Laymert Garcia. Propriedade intelectual ou direitos intelectuais coletivos? In. ARAÚJO, Ana Valéria e CAPBIANCO, João Paulo (Orgs.). Biodiversidade e proteção do conhecimento de comunidades tradicionais. São Paulo: ISA - Instituto Socioambiental, $\mathrm{n}^{\circ} .2$, 1996.

SHIVA, Vandana. Biopirataria: a pilhagem da natureza e do conhecimento. Petrópolis: Vozes, 2001.

SHIVA, Vandana. Monoculturas da Mente: Perspectivas da Biodiversidade e da Biotecnologia. São Paulo: Gaia, 2003.

THE OBAMA ADMINISTRATION. NATIONAL BIOECONOMY BLUEPRINT. The White House: Washington. April 2012. Disponível em: <https://obamawhitehouse.archives.gov/sites/default/files/microsites/ostp/national_bioeconom y_blueprint_april_2012.pdf>. Baixado em: 21/09/2020. 